\title{
Dissolution Process and Dissolved State of Cellulose in Dimethylformamide-Chloral-Pyridine System
}

\author{
Kenji KAMIDE, Kunihiko OKaJIMA, Toshihiko MATSUI, \\ and Sei-ichi MANABE \\ Textile Research Laboratory, Asahi Chemical Industry Co. Ltd., \\ 11-7 Hacchonawate-machi, Takatsuki, Osaka 569, Japan.
}

(Received March 27, 1980)

\begin{abstract}
The dissolution process and dissolved state of cellulose into a dimethylformamide-chloral-pyridine (D-C-P) system were studied by optical microscopy, nuclear magnetic resonance (NMR), polarimetry, infrared (IR) spectroscopy, and X-ray diffraction method. Natural cellulose with crystal form I dissolves rapidly at room temperature, via hemiacetaltype reaction with chloral, in which pyridine acts as a reaction accelerator. Cellulose exists as cellulose trichlorate in the mixture. When the pretreatment period of cellulose with dimethylformamide (DMF) is short, the cellulose dissolves into the system without swelling. But when the pretreatment period is relatively long, the cellulose swells considerably and then dissolves. Cellulose monochlorate was recovered by casting from the solution but cellulose trichlorate could not be isolated, probably because of the considerable tendency of the polymer to hydrolyze, especially when the solution is acidic. Cellulose having the crystal form II was regenerated by addition of water to the solution.
\end{abstract}

KEY WORDS Cellulose Chlorate / Dissolution Process / Dissolved State / Dimethylformamide-Chloral-Pyridine System/

Cellulose, which differs from row fossil material, is synthesized in cellular tissue from $\mathrm{CO}_{2}$ and $\mathrm{H}_{2} \mathrm{O}$ by the aid of solar energy and is then reproducible. Moreover, the cost of production is not so expensive as the starting polymeric material if the highstereoregular configuration and complicated chemical structure are taken into consideration. Cellulose has so far been utilized especially in fiber and paper industries, which may not be regarded as making the most use of this material. The recent energy situation undoubtedly gives importance to the need for greater possible utilization of cellulose materials. Thus, the dissolution of cellulose in organic media may open the new way for the chemical modification of cellulose, graft-polymerization onto cellulose, new cellulose fiber process and so forth. In this connection, the authors ${ }^{1}$ have published attempts to dissolve cellulose in organic media. For example, aliphatic amine oxide (1939), organic solvents in liquid $\mathrm{N}_{2} \mathrm{O}_{4}$ (1947), chloral-pyridine (1950), polyphenols-pyridine (1950), anhydrous trifluoroacetic acid (1952), bis $(\alpha, \beta$-dihydroxypropyl) disulfide (1965), $\mathrm{SO}_{2}$-amines (1966), $\mathrm{N}_{2} \mathrm{O}_{4}-$
DMSO (1966), NOCl-DMF (1966), $\quad N$ ethylpyridium chloride (1969), DMSO- $\mathrm{CS}_{2}$-amines (1969), $\quad N$-methylmorphorine $N$-oxide (1968), methylamine-DMSO (1971), paraformaldehydeDMSO (1975), hydradine (1976), and $\mathrm{N}_{2} \mathrm{O}_{4}$ (or chloral, $\mathrm{SO}_{2}$-amines) dissolved in many organic solvents (1968-1972) have been reported suitable as cellulose solvents. It should be noted that in most solvents, cellulose dissolves in the form of cellulose derivatives or complexes and is not moleculary dispersed as cellulose itself.

Of these solvents, chloral-pyridine system was the first discovered by Meyer ${ }^{2}$ and later this system was extended to include the chloral-solvents by Nakao et al. ${ }^{3}$ Clermont et al. ${ }^{4}$ have pointed out that the addition of a small amount of pyridine to the DMFchloral system facilitates the dissolution of cellulose and employed the system as a homogeneous acetylation media for cellulose. Recently, a similar attempt was also made by Ishizu et al. ${ }^{5}$ to obtain chlorinated cellulose by using the $\mathrm{D}-\mathrm{C}-\mathrm{P}$ system as a chemical modification media for cellulose. However, none of these authors have clarified the 
dry nitrogen through the desicator and evaporating solvents, a film was formed. This film was vacuumdried at $30^{\circ} \mathrm{C}$ for $12 \mathrm{~h}$, followed by washing with carbon tetrachloride, and subjected to the elemental analysis of chlorine and IR spectroscopic analysis (see Section Miscellaneous). White cellulose powder was regenerated by pouring the DMF-diluted cellulose solution of the D-C-P system into water under stirring, washed with water, dried in air and finally vacuum-dried at $70^{\circ} \mathrm{C}$ for $8 \mathrm{~h}$. The sample was also subjected to chlorine analysis, viscometry (in cadoxene at $25^{\circ} \mathrm{C}$ ), wide-angle $\mathrm{X}$-ray diffraction, and IR spectroscopic analysis.

\section{Polarimetry}

The hemiacetal reaction between chloral and levulose as a model compound of cellulose in DMF with or without pyridine was studied by polarimetry. For this purpose, the angle of optical rotation of the solution, in which levulose was dissolved in DMF at a concentration of $50 \mathrm{mg} \mathrm{dl}^{-1}$, was recorded as a function of reaction time with a DIP 181-type polarimeter (JASCO). Levulose was chosen for it's complete dissolution in DMF, giving a constant $[\alpha]$ value $\left([\alpha]_{589}^{25}=-20.5^{\circ}\right)$. When pyridine was used as the catalyst DMF-pyridine was fixed at a ratio of $10 / 1(\mathrm{~mol} / \mathrm{mol})$. In preliminary experiments, hydroquinone contained in chloral, and the solvents used showed no optical rotation.

\section{NMR Spectroscopy}

Spectra were recorded on a NMR spectrometer model PMX 60 (JEOL). The polymerization ability of chloral in solvents or in solvent mixtures was examined by analyzing the intensity of $\mathrm{CH}$ and $\mathrm{OH}$ proton signals. The reactivity of methanol and Dglucose as cellulose model compounds towards chloral was also examined in D-C-P $(5 / 1 / 1.2$, $\mathrm{mol} / \mathrm{mol} / \mathrm{mol})$. The NMR spectrum of cellulose in D-C-P $(2.5 / 1 / 1.2, \mathrm{~mol} / \mathrm{mol} / \mathrm{mol})$ was also recorded. In preparing sample solutions, cellulose and cellulose model compounds were first dispersed in DMF- $d_{7}$, followed by the addition of chloral and pyridine- $d_{5}$. The concentrations of D-glucose and cellulose were 11.25 and $0.45 \mathrm{wt} \%$, respectively.

\section{Electroconductivity}

The specific electroconductivities $k\left(\Omega^{-1} \mathrm{~cm}^{-1}\right)$ of binary solvent mixtures (D-C or $\mathrm{C}-\mathrm{P}$ ) were measured by a conventional method, using a platinium black electrode, followed by the dropwise addition of chloral into each $30 \mathrm{ml}$ of solvent (D or P) $3 \mathrm{~min}$ later. The $k$ values for purified DMF and pyridine were $10^{-8}$ and $10^{-7}\left(\Omega^{-1} \mathrm{~cm}^{-1}\right)$, respectively.

\section{Molecular Weight of Cellulose}

The viscosity-average molecular weights of the original cellulose, acid-hydrolyzed cellulose, and the regenerated cellulose from the $\mathrm{D}-\mathrm{C}-\mathrm{P}$ system were each determined from the limiting viscosity number $[\eta]$ in cadoxene at $25^{\circ} \mathrm{C}$, using the following equation, $[\eta]=3.85 \times 10^{-2} M_{w}^{0.76}$ where $M_{w}$ is the weight-average molecular weight.

\section{Miscelleneous}

The chlorine content of the cellulose derivative film and the water-regenerated cellulose powder were determined by the micro-combution method proposed by White. $^{\text {? }}$

IR spectra were recorded on a modified IR-430type spectrophotometer (Shimadzu Co. Ltd.). Powder samples were measured by $\mathrm{KBr}$ disk method, liquid samples by solvent-compensation method. The repeat scanning method was applied to the kinetic study of the dichloroketene formation ( $\mathrm{HCl}$ elimination reaction) from chloral molecule in DMF or pyridine, using a liquid cell (thickness, $0.025 \mathrm{~mm}$ ).

$\mathrm{X}$-ray diffraction patterns for the product from the mixture of $\mathrm{C}-\mathrm{P}(1 / 1, \mathrm{~mol} / \mathrm{mol})$, polychloral, and the water-regenerated cellulose were recorded on a Rotar Flex RU-200PL (Rigaku Denki Co. Ltd.). In the case of a paste-like sample the symmetrical reflection technique was applied, by sandwiching it between aluminum foil; in other case, the symmetrical transmission technique was applied.

\section{RESULTS AND DISCUSSION}

\section{Screening of the Effective Solvent}

In Table II, the solubility behavior of cellulose in binary mixtures containing chloral is summarized along with some of the physical properties of these solvents. Sulfoxides and amides such as dimethyl sulfoxide (DMSO), DMF, dimethylacetamide (DMAc) are obviously the only effective solvents for dissolving cellulose, when mixed with chloral. Nakao et al. ${ }^{3}$ were the first to discover the dissolving power of these solvents-chloral systems. These binary mixtures require more than $30 \mathrm{~h}$ to com- 
pletely dissolve cellulose at room temperature. The co-existence of amines in these binary mixtures conspicuously shortens the dissolving time. We observed that under optimized conditions, cellulose can be dissolved within a few minutes in sulfoxide (or amide)-chloral-amine systems. Solvents effective for dissolving cellulose, when mixed with chloral and amines, are strictly limited to sulfoxides and amides as in the case of binary mixtures. Polymerized chloral and other aldehydes (except for formaldehyde) were, in contrast to chloral, found to have no ability for dissolving cellulose.

All the effective solvents screened here have large electro-negativity (EN) and large dielectric constant $(\varepsilon)$, and accordingly exhibit a strong swelling power toward cellulose. Moreover, these solvents are characterized by the electron conjugation system on the molecular level, since they are proton-donners having oxygen atoms as active centers, resulting in large dipole moments (DMSO; 4.3D; DMF, 3.82D; DMAc, 3.79D).

Amines, which cannot dissolve cellulose, when mixed with chloral, were found to strongly accelerate the cellulose dissolution when mixed with sulfoxide (or amide)-chloral yielding ternary mixtures. Pyridine ${ }^{4}$ and triethylamine apply to this case and are characterized by high $\mathrm{EN}$ and low $\varepsilon$. A lone pair electron on a nitrogen atom of an amine may activate the carbonyl group of chloral, suggesting the possibility of a reaction between chloral and cellulose during the dissolving process.

Table III gives the solubility behavior of cellulose samples of different crystal form in D-C-P $(3.7 / 1 / 1.2, \mathrm{~mol} / \mathrm{mol} / \mathrm{mol})$ at $25^{\circ} \mathrm{C}$. As far as the experimental conditions are concerned, only natural cellulose (crystal form I) can be dissolved in the system. The reasons for this phenomenon are not fully clear at the present, but the layered structure and fibrillate character of natural cellulose may play an important role in it's dissolution in the D-C-P system.

The Optical Microscopic Observation for the Dissolving Process of Cellulose in the $D-C-P$ System

Figure 1 shows polarized microscopic photographs for cellulose in D-C-P (3.7/1/1.2, $\mathrm{mol} / \mathrm{mol} / \mathrm{mol}$ ). Photographs of the A series denote the case in which the period of dipping of cellulose in DMF was $8 \mathrm{~min}$, in the B series, the time was $20 \mathrm{~min}$. The number under each photograph indicates the time elapsed (in min), measured from the instant the pyridine was added to the mixture of cellulose-D-C. The dissolving process of cellulose in the D-C-P system depends considerably on the dipping period in DMF: When the dipping time was short $(8 \mathrm{~min})$, dark narrow bands appeared with a period of $50-100 \mu \mathrm{m}$, perpendicular to fiber axis of the fibril. This fibril was bright under polarized microscope, and decomposed into small particles

Table III. Influence of cellulose crystal form on the solubility in D-C-P system

\begin{tabular}{|c|c|c|c|c|}
\hline Sample code & Treatment & $\mathrm{N}$ or $\mathrm{R}^{\mathrm{c}}$ & $\begin{array}{c}\text { Crystal } \\
\text { form }\end{array}$ & Solubility $^{\mathrm{d}}$ \\
\hline 1 & None & $\mathrm{N}$ & I & $\bigcirc$ \\
\hline 2 & None & $\mathrm{N}$ & I & $\bigcirc$ \\
\hline 3 & None & $\mathrm{N}$ & I & $\bigcirc$ \\
\hline 4 & None & $\mathbf{R}$ & II & $\times$ \\
\hline 5 & None & $\mathbf{R}$ & II & $\times$ \\
\hline $6-2-1^{a}$ & $8 \% \mathrm{NaOH}$, water at $28^{\circ} \mathrm{C}$ & $\mathbf{R}$ & I & $\bigcirc$ \\
\hline $6-2-2^{a}$ & $14 \% \mathrm{NaOH}$, water at $95^{\circ} \mathrm{C}$ & $\mathbf{R}$ & I and II & $\triangle$ \\
\hline $6-2-3^{a}$ & $20 \% \mathrm{NaOH}$, water at $28^{\circ} \mathrm{C}$ & $\mathbf{R}$ & II & $\times$ \\
\hline $6-2-4^{a}$ & $20 \% \mathrm{NaOH}$, water at $95^{\circ} \mathrm{C}$ & $\mathbf{R}$ & II & $\times$ \\
\hline $6-4-1^{b}$ & $20^{\circ} \% \mathrm{NaOH}$, water at $28^{\circ} \mathrm{C}$ & $\mathbf{R}$ & II & $\times$ \\
\hline
\end{tabular}

a Cellulose (code 2) was mercelized.

b Cellulose (code 4) was mercelized.

c $\mathrm{N}$ and $\mathrm{R}$ denote "natural" and "regenerated," respectively.

d $O$, completely dissolved; $\triangle$, partially dissolved; $\times$, not dissolved. 


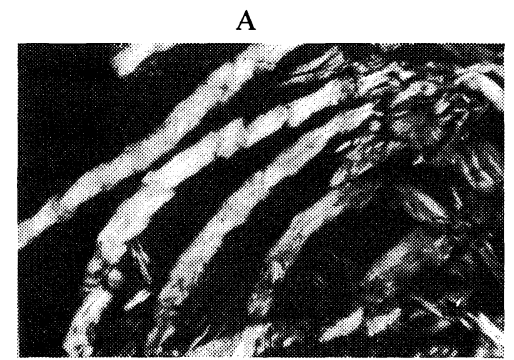

7

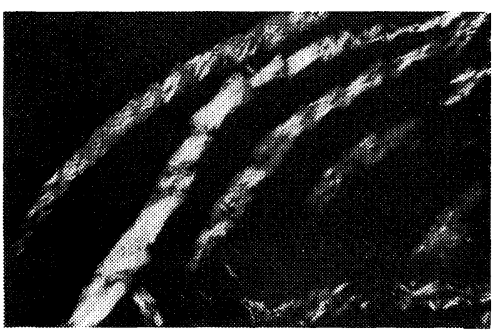

9

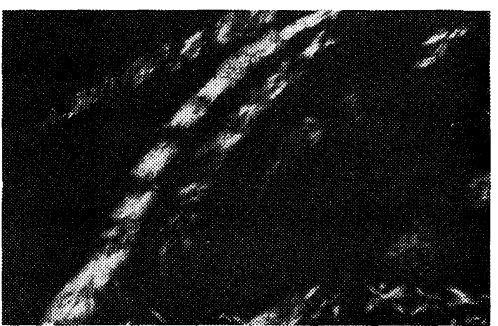

12

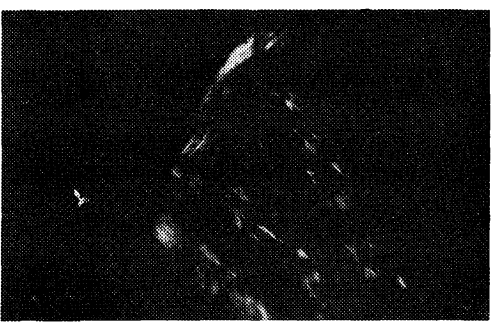

20

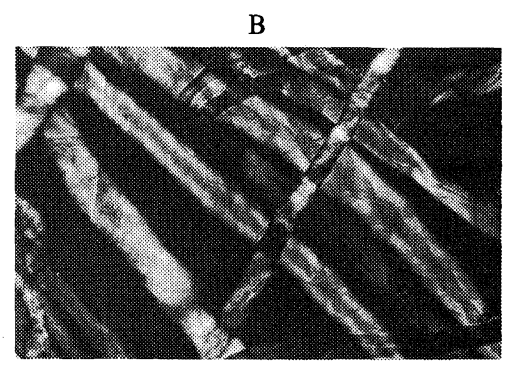

6

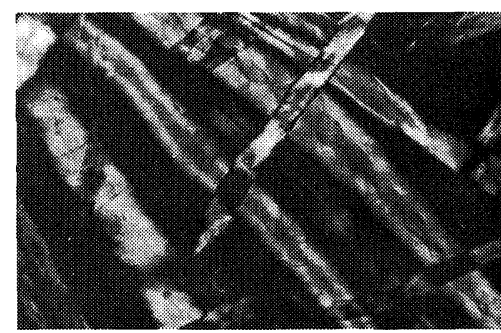

10

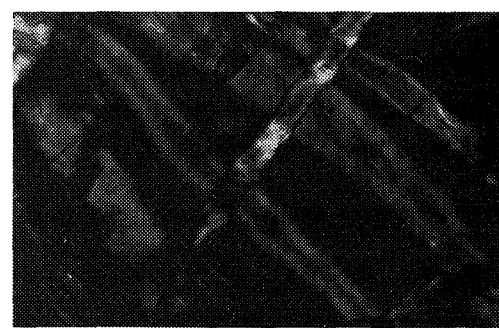

13

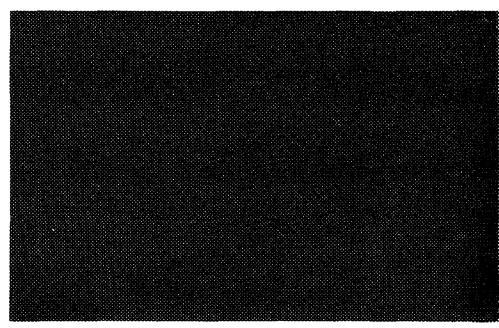

20

Figure 1. The polarized microscopic photographs of the cellulose dissolving process in D-C-P system: A, the case where the pre-dipping interval of cellulose in DMF is $8 \mathrm{~min}$; $\mathrm{B}$, the case this period is $20 \mathrm{~min}$. The number under each photograph indicates elapsed time (in $\mathrm{min}$ ) measured from the instant pyridine was added to the mixture of cellulose-D-C.

which finally dissolved in the solvent mixture. From these observations, we may consider that wood pulp has a periodicity from 50 to $100 \mu \mathrm{m}$, and to which the solvent is much more accessible. This periodicity corresponds well to the helix period of the fibril, ${ }^{8}$ although this helical structure can not be observed directly. On the other hand, when the dipping time is relatively long $(20 \mathrm{~min})$, the entire cellulose fiber 
swells immediately following the addition of pyridine, and the helical structure can be seen particularly well in the center part of fiber along the fiber axis. Similar phenomena have been observed for greartly swollen cellulose when phosphoric acid, cuprammonium solution, ${ }^{9}$ and cadoxene $^{10}$ were used. The regenerated cellulose including viscose and cuprammonium rayons neither swell nor dissolve in the D-C-P system.

The big differences in the dissolving processes (series A and B) of cellulose in the D-C-P system may be due to the respective difference in the degree of penetration of DMF into the inner part of fibril. In the latter case, DMF, which penetrated into the fibril may facilitate the penetration of a mixture of C-P, causing swelling and some sort of chemical reaction with cellulose. In contrast to this, in the former case, D-C-P mixture may react with accessible parts of cellulose and dissolve it as shown in Figure 1A. Without pyridine, cellulose does not swell remarkably, and does not dissolve since stirring is not possible when carrying out microscopic observation. Thus, we may conclude that pyridine acts as an accelerator for the reaction between cellulose and chloral or as a carrier for chloral probably through the formation of a complex.

\section{Interaction between Solvent Components}

Figure (2a) shows a phase-diagram of the ternary mixture, (not including cellulose), by weight fraction at $20^{\circ} \mathrm{C}$. In the figure, the solution in region $\mathrm{I}$ is homogeneous and in region II, the mixture of the components produces a white viscous product at $20^{\circ} \mathrm{C}$, but can be made into a homogeneous solution by heating. In region III, chloral precipitates as a white powder through polymerization. This white powder was identified as polychloral by IR.

Figure (2b) shows a phase-diagram of the cellulose-D-C-P system. The multi-dotted region is the area in which the cellulose dissolves rather rapidly. This phase-diagram was made in the following manner. A dried cellulose sample was first treated with a given amount of DMF for $3-5 \mathrm{~min}$ and then a given amount of chloral followed by pyridine was added, (final cellulose concentration, $3 \mathrm{wt} \%$ ). The dissolving process of cellulose could be observed with naked eye. The numbers on the full straight lines in the diagram denote the molar ratio of the corresponding two components. The solventmixture capable of dissolving cellulose exsisted, of

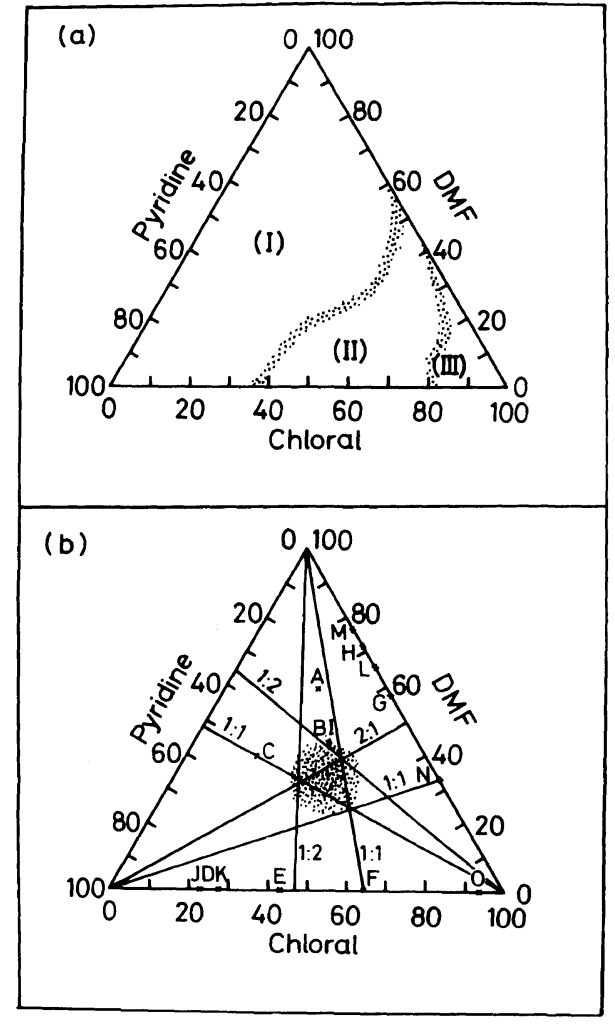

Figure 2(a). Phase diagram of the ternary mixture of D-C-P by weight fraction at $20^{\circ} \mathrm{C}: \mathrm{I}$, the region where the homogeneous solution is made; II, the region where homogeneous solution can be made by heating; III, the region where chloral precipitates as a white powder.

Figure 2(b). Phase diagram of the cellulose-D-C-P mixture. The numbers on the straight lines denote the molar ratio between the corresponding two components. The multi-dotted area denotes the region in which cellulose dissolves rather rapidly.

course, in region I in Figure 2(a).

An NMR study confirmed that in those solventmixtures having compositions corresponding to positions A, B, C, and D in Figure 2(b), chloral was neither converted into it's hydrate,. dimer nor into the polymer. At $\mathrm{G}$ and $\mathrm{L}$ positions in Figure 2(b) $(\mathrm{D} / \mathrm{C}=2.5 / 1$ and $5 / 1, \mathrm{~mol} / \mathrm{mol}$, respectively), the chloral hydrate and it's oligomer were found to be produced. The NMR spectrum for the G mixture is shown in Figure 3. The aldehyde proton singlet for chloral was found at $9.44 \mathrm{ppm}$. In an amplified spectrum of the region $5.20-6.00 \mathrm{ppm}$, signals for the $\mathrm{CH}$ proton of chloral hydrate, its dimer, and 


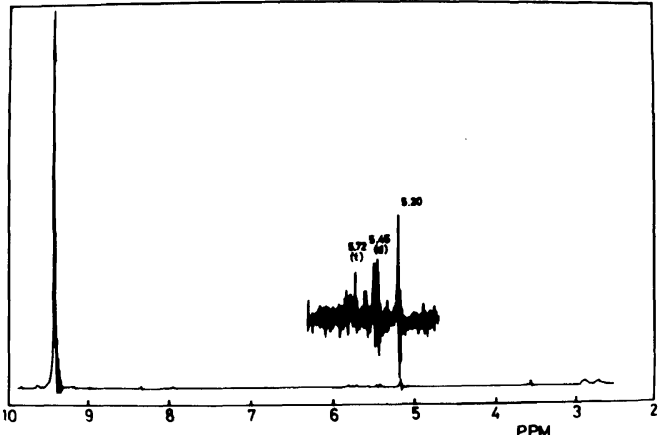

Figure 3. NMR spectrum of the mixture of DMF and chloral $(\mathrm{D} / \mathrm{C}=2.5 / 1, \mathrm{~mol} / \mathrm{mol})$ at the point $\mathrm{G}$ in Figure 2(b).

trimer were detected at 5.72 (triplet), 5.45 (doublet), and 5.20 (singlet) ppm, respectively for the G mixture. Analysis of the NMR peak intensity indicated that the convertion of chloral into these compounds in the $\mathrm{G}$ mixture is less than $5 \%$ and can be ignored. A conspicuous broad signal around $10 \mathrm{ppm}$ on the NMR spectrum (Figure 3) is attributable to the $\mathrm{HCl}$ proton. Other experimental evidence of $\mathrm{HCl}$ formation in the system is illustrated in Figure 4, where change in the specific electro-conductivity of the system is plotted as a function of the amount of chloral added to the DMF or pyridine. An increase in the specific electroconductivity with the stepwise addition of chloral suggests the formation of new ionic species in the system. Thus, the system has the potential ability to produce $\mathrm{HCl}$ and dichloroketene by the decomposition of chloral as shown in eq 1 .

$$
\mathrm{Cl}_{3} \mathrm{C}-\mathrm{C}_{\mathrm{H}}^{2 / \mathrm{O}} \longrightarrow \mathrm{HCl}+\mathrm{Cl}_{2} \mathrm{C}=\mathrm{C}=\mathrm{O}
$$

The conversion of chloral into $\mathrm{HCl}$ (or dichloroketene) was estimated from the peak intensity concerned in Figure 3 to be $12 \%$ of the chloral initially charged. The detailed kinetics of this reaction will be discussed later.

Figure 5 shows a comparison of the X-ray diffraction pattern for the viscous white product (a) produced in the $\mathrm{F}$ mixture $(\mathrm{C} / \mathrm{P}=1 / 1, \mathrm{~mol} / \mathrm{mol})$, the polychloral (b) produced in the 0 mixture $(\mathrm{C} / \mathrm{P}=10 / 1, \mathrm{~mol} / \mathrm{mol})$ in Figure $2(\mathrm{~b})$ and pure

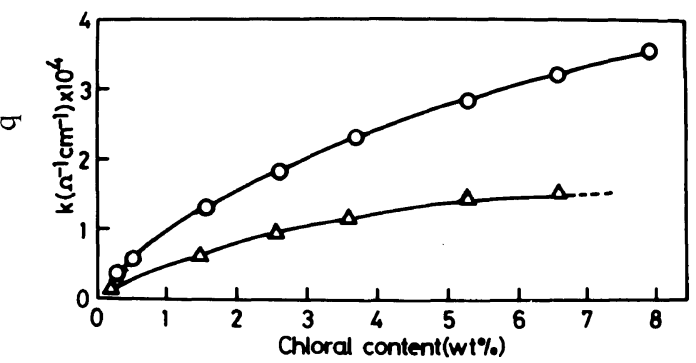

Figure 4. Change in the specific electroconductivity, $k$, of the binary mixture of chloral and DMF $(O)$ or pyridine $(\triangle)$ as a function of chloral content.

polychloral (c). ${ }^{11}$ The last two of these products were identified to be the same from stand point of IR. The difference in X-ray diffraction patterns between (b) and (c) seems to result from the different preparation conditions. The X-ray diffraction pattern of the white viscous product (a) exhibits very different patterns from those in (b) and (c), showing new peaks at $2 \theta=24^{\circ}$ and $28^{\circ}$, and a difused peak at $2 \theta=10^{\circ}$. Other peaks are almost same as those in (b) and (c), suggesting that the product (a) is crystalographically different from (b) and (c), but is almost polychloral, containing a considerable amount of pyridine. The composition of the product (a) from the $\mathrm{F}$ mixture $(\mathrm{C} / \mathrm{P}=1 / 1$, $\mathrm{mol} / \mathrm{mol}$ ) was found to be exactly $\mathrm{C} / \mathrm{P}=1 / 1$ ( $\mathrm{mol} / \mathrm{mol}$ ) by NMR analysis. Moreover, NMR analysis for the upper liquid layer of the the mixture $(\mathrm{C} / \mathrm{P}=1 / 2, \mathrm{~mol} / \mathrm{mol})$, in which the white viscous product was also produced, confirmed again that the composition of the white viscous product was $\mathrm{C} / \mathrm{P}=1 / 1(\mathrm{~mol} / \mathrm{mol})$. Thus, it may be concluded that pyridine has a strong affinity toward polychloral, resulting in equimolar viscous products capable of being converted into a homogeneous liquid owing to the decomposition of polychloral ${ }^{11}$ by heating. Thus, we can anticipate equimolar complexes (I) of chloral and pyridine as intermediates for the white viscous product (II), as illustrated in eq 2 . The coordination of a lone pair electrons of a nitrogen atom of pyridine with the carbonyl carbon of chloral in complex (I), can be explained by the shift of carbonyl absorption band of chloral towards lower wave number $\left(1768 \mathrm{~cm}^{-1}\right.$ to $\left.1760 \mathrm{~cm}^{-1}\right)$ in IR spectrum when chloral is mixed with pyridine. 
<smiles></smiles>

(I)<smiles>OC(n1cccc1)C(Cl)(Cl)Cl</smiles>

(II)
As a result, the existence of pyridine accelerates the hemiacetal-type reaction of chloral with $\mathrm{ROH}$, probably through the formation of complex (I), as shown in eq 3 ,

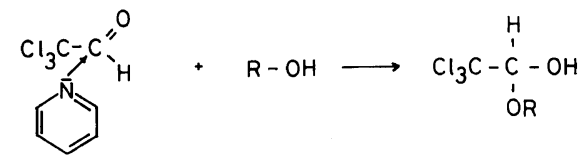

It should be noted that under optimized conditions for the dissolving of cellulose in D-C-P system, the molar ratio of $\mathrm{C}-\mathrm{P}$ is also nearly unity. In this respect, DMF acts as solvent for the equimolar viscous product of $\mathrm{C}-\mathrm{P}$. Based on the comments above, we may consider two different chemical reactions in the dissolution process of cellulose into the D-C-P system. One is the hemiacetal-type reaction (eq 3 ), and the other is the dichloroacetylation of cellulose (eq 4) since the system has been proved to produce $\mathrm{HCl}$ and dichloroketene.

$$
\mathrm{Cl}-\mathrm{C}=\mathrm{C}=\mathrm{O}+\mathrm{ROH} \longrightarrow \stackrel{\mathrm{Cl}}{\mathrm{Cl}} \underset{\mathrm{H}}{\mathrm{C}}-\underset{\mathrm{OR}}{\mathrm{C}}=\mathrm{O}
$$

Next, we will determine which is the main route in the dissolution process of cellulose in the D-C-P system.

\section{Reaction between Cellulose and Chloral}

Figure 6(a) and (b) show the NMR spectra of the mixture of methanol (as a model compound of cellulose)-D-C-P and the D-C-P (3.7/1/1.2, $\mathrm{mol} / \mathrm{mol} / \mathrm{mol}$ ) mixture, respectively. In the case of the first spectrum, methanol was added to the D-P mixture, followed by the addition of chloral. Three new single peaks appeared at 3.35, 3.54, and 4.98 . ppm on the spectrum for the methanol-D-C-P system, but not for the D-C-P system. The peak at $3.35 \mathrm{ppm}$ is assigned to methyl single peak for unreacted methanol. The intensity ratio of the peaks at $3.54 \mathrm{ppm}$ and $4.98 \mathrm{ppm}$ is 3 , indicating the formation of compound (III) in eq 5 .<smiles>COC(O)C(Cl)(Cl)Cl</smiles>

The peaks at 3.54 and $4.98 \mathrm{ppm}$ are, respectively, attributable to methyl and methine protons for compound (III). The corresponding $\mathrm{OH}$ signal for

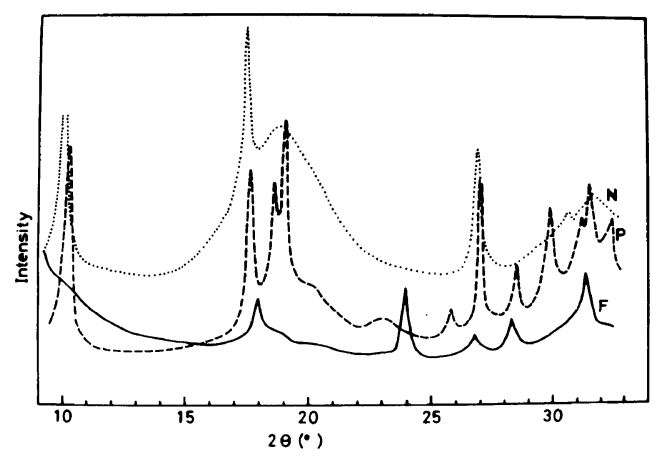

Figure 5. X-ray diffraction patterns of the white viscous product, produced from the mixture $(C / P=1 / 1$, $\mathrm{mol} / \mathrm{mol}$ ) at point $\mathrm{F}$ in Figure 2(b) (full line), polychloral, produced from the mixture $(\mathrm{C} / \mathrm{P}=10 / 1, \mathrm{~mol} / \mathrm{mol})$ at point $\mathrm{N}$ in Figure 2(b) (dotted line) and pure polychloral, prepared by the ordinary method (broken line).

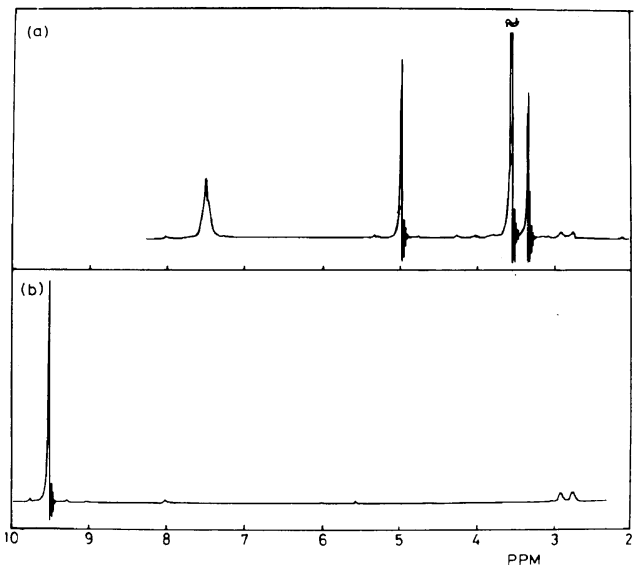

Figure 6. ${ }^{1} \mathrm{H}$ NMR spectra of mixtures methanolD-C-P $(1.5 / 3.7 / 1 / 1.2, \quad \mathrm{~mol} / \mathrm{mol} / \mathrm{mol} / \mathrm{mol}) \quad$ (a), and D-C-P $(3.7 / 1 / 1.2, \mathrm{~mol} / \mathrm{mol} / \mathrm{mol})(\mathrm{b})$. 
compound (III) was detected, by deuteration, at $8.38 \mathrm{ppm}$. The $\mathrm{HCl}$ peak was not visible on either spectra (Figure 6(a) and (b)). Accordingly, the hemiacetal-type reaction as shown in eq 5 occurs predominantly.

Figure 7(a) and (b) show the NMR spectra for Dglucose in the D-P $(3.7 / 1, \mathrm{~mol} / \mathrm{mol})$ and the D-C-P $(4 / 1.45 / 1, \mathrm{~mol} / \mathrm{mol} / \mathrm{mol})$, respectively. In the latter figure, the amount of chloral added was slightly in excess of an equimolar amount of $\mathrm{OH}$ from Dglucose. The solubility of D-glucose in the D-P mixture was extremely low, but D-glucose dissolved quickly in the D-C-P mixture, containing an excessive chloral, being more than an equimolar amount of $\mathrm{OH}$ from D-glucose. The former spectrum resembles very much that in $\mathrm{D}_{2} \mathrm{O},{ }^{12}$ indicating that the peaks at 4.60 and $5.20 \mathrm{ppm}$ are attributable to anomeric $\mathrm{CH}$ protons at the $\mathrm{C}-1$ position ( $\alpha$ and $\beta$ anomer, respectively) and the peaks at the region 3.0-4.1 ppm attributable to the remaining $\mathrm{CH}$ and $\mathrm{CH}_{2}$ protons on the glycoside ring. $\mathrm{OH}$ signals may perhaps be included in the region $4.0-5.8 \mathrm{ppm}$. When D-glucose is dissolved in D-C-P system, the NMR spectrum (Figure 7(b)) becomes complicated. $\mathrm{CH}$ and $\mathrm{CH}_{2}$ proton signals can be seen as two envelopes in the region $3.0-5.2 \mathrm{ppm}$; this region is the same as that for the signals of D-glucose in D-C. Signals in the region $5.25-6.4 \mathrm{ppm}$ are attributable to the $\mathrm{CH}$ protons, attached to D-glucose for the chlorate residue. This is because of the high

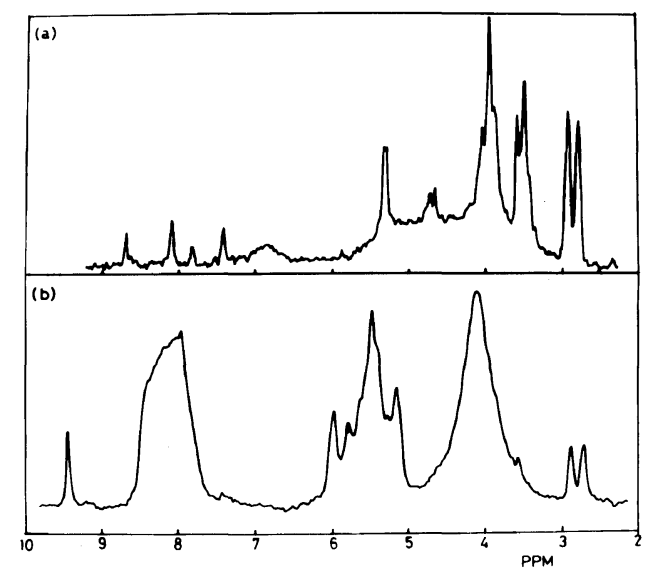

Figure 7. ${ }^{1} \mathrm{H}$ NMR spectra $\mathrm{D}$-glucose in D-P (3.7/1, $\mathrm{mol} / \mathrm{mol}$ ) (a) and D-glucose in $\mathrm{D}-\mathrm{C}-\mathrm{P} \quad(4 / 1.45 / 1$, $\mathrm{mol} / \mathrm{mol} / \mathrm{mol}$ ) (b). deshielding effect of chlorine atoms resulting the shift of $\mathrm{CH}$ proton signals to a lower field. In Figure 7 (b), the ratio of the area under the envelopes between $3.0-5.20 \mathrm{ppm}$ and $5.25-6.4 \mathrm{ppm}$ is estimated to be about 1.4. This value is in good agreement with the theoretical value (1.40), calculated by assuming that (1) all the $\mathrm{OH}$ on D-glucose react with chloral to produce D-glucose pentachlorate and (2) the peaks at $3.0-5.2 \mathrm{ppm}$ are due to $\mathrm{CH}$ and $\mathrm{CH}_{2}$ proton signals on the glycoside ring and the peaks at $5.25-6.4 \mathrm{ppm}$ are due to $\mathrm{CH}$ proton signals of the chlorate residue, reacted with D-glucose. The corresponding $\mathrm{OH}$ signals for the chlorate residue can be seen at $7.8-8.0 \mathrm{ppm}$ displaying various activities. The $\mathrm{OH}$ region has already been deternined by NMR analysis for the reaction of methanol and chloral. The spectra in the region 7.8-8.0 ppm become complicated with the co-existence of the $\gamma$-proton signal of pyridine (7.8 $\mathrm{ppm})$ and the formyl proton signal of DMF (8.08 $\mathrm{ppm}$ ). The aldehyde proton signal for unreacted chloral was detected at $9.52 \mathrm{ppm}$. The ratio of the peak area at 9.52 to that at $7.8-8.0 \mathrm{ppm}$ provides a rough estimation of the amount of chloral, reacted with D-glucose. That is, by this analysis, it becomes clear that 5 moles of chloral react with $1 \mathrm{~mol}$ of $\mathrm{D}$ glucose. In other words, all the $\mathrm{OH}$ of D-glucose reacted with chloral. The ratio of area under peaks due to $\mathrm{OH}$ signal $(7.8-8.0 \mathrm{ppm})$ to that due to $\mathrm{CH}$ signal (3.5-6.4 ppm) was found to be 2.33 , which is very near to the theoretical value (2.40), calculated for D-glucose pentachlorate. In summery, a hemiacetal-type reaction occurs predominantly when ROH exists in the system.

Thus, we have attempted to confirm the predominancy of the hemiacetal reaction in a much more general manner, using cellulose instead of Dglucose. Figure 8 shows the NMR spectrum for cellulose in D-C-P $(2.5 / 1 / 1.2, \mathrm{~mol} / \mathrm{mol} / \mathrm{mol})$ system. The whole spectrum is very similar to that of Dglucose in D-C-P system. The $\mathrm{CH}$ and $\mathrm{CH}_{2}$ proton signals on the glycoside ring are significantly visible in the region $3.2-5.0 \mathrm{ppm}$. This region is located in a considerably lower field than that for lowmolecular-weight cellulose-DMSO system (3.2-4.0 $\mathrm{ppm}),{ }^{13}$ indicating that, in the former system, certain chemical reactions occur significantly. $\mathrm{CH}$ signals observed at $5.0-6.0 \mathrm{ppm}$ are attributable to the $\mathrm{CH}$ of the chlorate residue, attached to glycoside residue, as a result of the hemiacetal reaction 


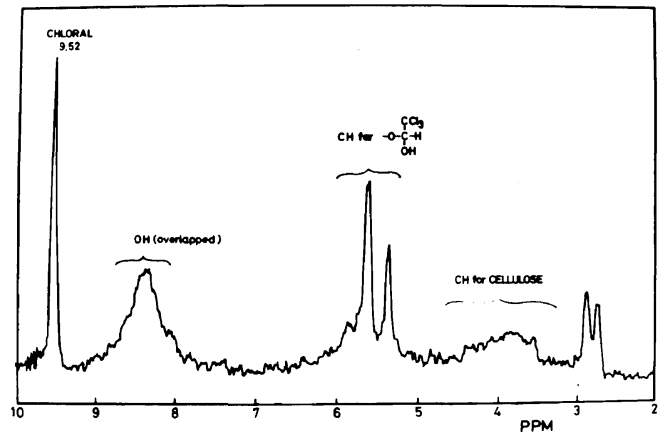

Figure 8. ${ }^{1} \mathrm{H}$ NMR spectrum of cellulose in D-C-P $(2.5 / 1 / 1.2, \mathrm{~mol} / \mathrm{mol} / \mathrm{mol})$.

between cellulose and chloral. This region may include signals for the $\mathrm{CH}$ protons at $\mathrm{C} 3$ (about 5.4 $\mathrm{ppm}$ ) and $\mathrm{C} 4$ (about $5.0 \mathrm{ppm})^{14}$ on the glycoside ring, as a result of etherification or esterification of the glycoside ring. Furthermore, the $\mathrm{CH}$ proton of the chloral hydrate or its dimmer, derived from the reaction between chloral and absorbed water, may contribute to the formation of the region $5.0-6.0$ $\mathrm{ppm}$, although but very slightly. $\mathrm{OH}$ signals were observed in the region $8.0-9.1 \mathrm{ppm}$ as overlapped multiplets, meaning that $\mathrm{OH}$ groups at various $\mathrm{C}$ positions on the cellulose react with chloral to give cellulose di- or tri-chlorate. In the region $8.0-9.1$ $\mathrm{ppm}$, there are a formyl proton signal $(8.08 \mathrm{ppm})$ for DMF, $\gamma-\mathrm{H}$ proton signal $(8.78 \mathrm{ppm})$ for pyridine and a $\mathrm{HCl}$ proton signal (centered at $9.00 \mathrm{ppm}$ ), and an $\mathrm{OH}$ proton signal derived from chloral hydrate or its dimer (this is a very small factor). Assuming that the $\mathrm{OH}$ region for cellulose chlorate is $8.08-8.70$ ppm and calculating the peak area ratio of total $\mathrm{OH}$ $(8.08-8.70 \mathrm{ppm})$ to total $\mathrm{CH}(3.5-6.5 \mathrm{ppm})$ we obtain experimentally 0.36 , which agree roughly with the theoretical value of 0.33 , calculated for cellulose trichlorate. Furthermore, the peak area ratio of the $\mathrm{CH}$ and $\mathrm{CH}_{2}$ region (3.5-5.4 ppm) on the glycoside ring to the $\mathrm{CH}$ region $(5.5-6.0 \mathrm{ppm})$ for the chlorate residue was found to be 0.92 . This value is also near the theoretical value (1.00) for cellulose trichlorate. The aldehyde proton coming from the remaining chloral is evident at $9.52 \mathrm{ppm}$. Although the $\mathrm{HCl}$ proton signal is visible in the spectrum, we could find no peak for dichloroacetylated cellulose, which must have appeared as a singlet around $7 \mathrm{ppm}$, just as the proton signal for the chloroform. Thus, we may conclude that cellulose is dissolved in the system in the form of cellulose trichlorate as a result of the hemiacetal reaction of cellulose with chloral and that there is the possibility that the formation of dichloroacetyl cellulose in the D-C-P system is not allowed.

Additional evidence supporting these conclusions can be obtained from kinetic studies of two reactions using IR spectroscopy and polarimetry, the hemiacetal reaction and $\mathrm{HCl}$ elimination reaction (dichloroketene formation). Figure 9 shows a plot of $-\log \left(\log I_{\mathrm{o}} / I\right) v s$. time for D-C or C-P binary system, where $I$ denotes the transmitted light intensity of the carbonyl absorption band $\left(1760 \mathrm{~cm}^{-1}\right)$ at $T=t$, and $I$, that of the base line of this absorption band, and M. L. K. J in the figure are mixtures whose compositions correspond to those in Figure 2(b). In these mixtures, a decrease in carbonyl absorption at $1760 \mathrm{~cm}^{-1}$ of chloral can be reasonably assumed, owing to dichloroketene formation, since polymerization of chloral and the reaction with water may be completely ignored, as was proved in section Interaction between Solvent Components. The linearity of the plots proves firstorder reaction kinetics. The rate constant of the dichloroketene formation, estimated from the slope of the plot, is much higher in DMF than in pyridine. This agrees well with experimental results obtained in the electroconductivity study. The rate constant $k_{1}$ was found to be $3.9 \times 10^{-4}\left(\mathrm{~s}^{-1}\right)$ for $\mathrm{M}(\mathrm{D} / \mathrm{C}=5 / 1, \mathrm{~mol} / \mathrm{mol})$.

Figure 10 shows a plot of the angle of optical rotation of the levulose-D-C system as a function of time. Curves $1-6$ were obtained for various molar ratios of chloral-OH contained in the

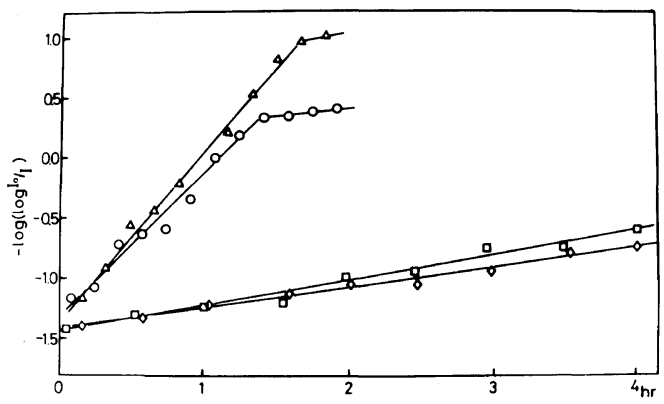

Figure 9. Plot of $-\log \left(\log I_{0} / I\right)$ vs. time: $\diamond, \mathrm{C} / \mathrm{P}=1 / 3$ $(\mathrm{mol} / \mathrm{mol}) ; \square, \mathrm{C} / \mathrm{P}=1 / 4 \quad(\mathrm{~mol} / \mathrm{mol}) ; \triangle, \mathrm{D} / \mathrm{C}=1 / 3$ $(\mathrm{mol} / \mathrm{mol}) ; \mathrm{O}, \mathrm{D} / \mathrm{C}=1 / 5(\mathrm{~mol} / \mathrm{mol})$. 


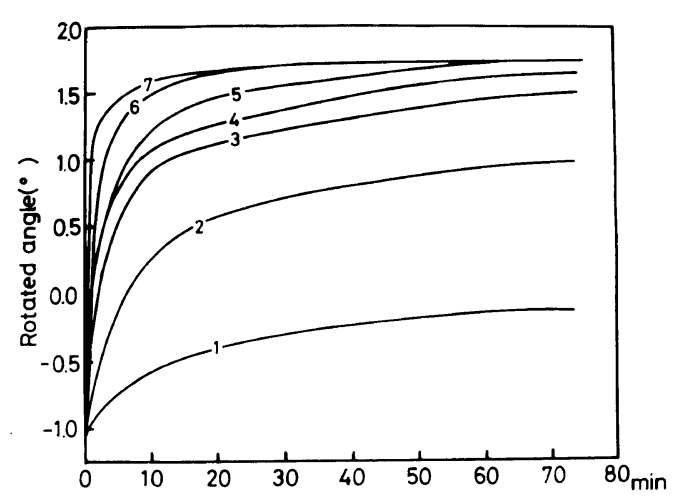

Figure 10. Plot of the angle of optical rotation of the levulose-D-C system: 1 , levulose/chloral $=1 / 1 \quad(\mathrm{~mol} /$ mol); 2 , levulose $/$ chloral $=1 / 2(\mathrm{~mol} / \mathrm{mol}) ; 3$, levulose $/$ chloral $=1 / 3 \quad(\mathrm{~mol} / \mathrm{mol}) ; \quad 4, \quad$ levulose $/$ chloral $=1 / 4$ $(\mathrm{mol} / \mathrm{mol}) ; 5$, levulose $/$ chloral $=1 / 5 \quad(\mathrm{~mol} / \mathrm{mol}) ; 6$, levulose $/$ chloral $=1 / 7 \quad(\mathrm{~mol} / \mathrm{mol}) ; 7$, levulose $/$ chloral $=$ $1 / 5(\mathrm{~mol} / \mathrm{mol})$ with pyridine.

levulose, where the molar ratio of OH-DMF was kept constant. Curve 7 represents the equimolar chloral-OH system, to which pyridine was added. It is obvious from the figure that all $\mathrm{OH}$ in the levulose reacts with chloral, since curves 5,6 , and 7 give the same saturated values for the angle of rotation. Owing to the presence of pyridine, the reaction is accelerated very much without change in the saturated value ( $c f$. curve 5). The rate constant of the reaction for curve 7 can be calculated in the following manner on the basis of second-order reaction rate equations,

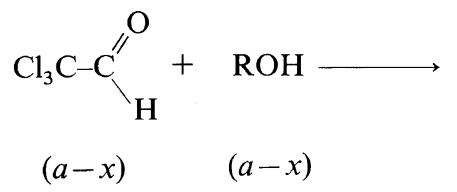<smiles>[R]OC(O)C(Cl)(Cl)Cl</smiles>

$(x)$

$$
\begin{gathered}
\frac{x}{0.139}=\frac{\theta_{t}-\theta_{0}}{\theta_{\infty}-\theta_{0}} \\
k_{2} t=\frac{x}{a(a-x)}
\end{gathered}
$$

where $a$ is the initial concentration $\left(0.139 \mathrm{~mol} \mathrm{dl}^{-1}\right)$, $x$, the amount of chlorate produced at given reaction time $(t), \theta_{0}$, angle of rotation at $t=0, \theta_{t}$, the angle of rotation at $t=t, \theta_{\infty}$, the angle of rotation at an infinite reaction stage, and $k_{2}$, the second-order reaction rate constant. In fact, the plot according to eq 8 gave a reasonably straight line and we obtained a $k_{2}$ value of $4.44 \times 10^{-1} \mathrm{dl} \mathrm{mol}^{-1}$. Cellulose can be dissolved within 10 minutes at room temperature in the D-C-P system provided optimized solvents are used, and this is about half of the time required for terminating the reaction for levulose. Assuming that the $k_{2}$ value, obtained for the levulose-D-C-P system, also holds in the case of cellulose, we may compare the reaction rates $(\mathrm{d} x / \mathrm{d} t)_{1}$ (eq 9) and $(\mathrm{d} x / \mathrm{d} t)_{2}$ (eq 10) for the dichloroketene formation and the hemiacetal reaction, respectively,

$$
\begin{aligned}
(\mathrm{d} x / \mathrm{d} t)_{1} & =k_{1}(a-x) \\
(\mathrm{d} x / \mathrm{d} t)_{2} & =k_{2}(a-x)^{2}
\end{aligned}
$$

where $a$ is the initial concentration of chloral and cellulose, expressed as $\mathrm{moldl}^{-1}$. By putting $k_{1}=3.9 \times 10^{-4}$ and $k_{2}=4.44 \times 10^{-1}$, and dividing eq 10 by eq 9 , eq 11 is obtained.

$$
(\mathrm{d} x / \mathrm{d} t)_{2} /(\mathrm{d} x / \mathrm{d} t)_{1}=1.12 \times 10^{3}(a-x)
$$

Since the dichloroketene formation and the hemiacetal reaction are probably competitive, if $(\mathrm{d} x / \mathrm{d} t)_{2} /(\mathrm{d} x / \mathrm{d} t)_{1}>1$, that is $(a-x)>0.9 \times 10^{-3}$, then the hemiacetal reaction will preferably take place. Under optimized conditions, the concentration of chloral is about $0.2 \mathrm{~mol} \mathrm{dl}^{-1}$ for the $\mathrm{D}-\mathrm{C}-$ $\mathrm{P}$ mixture $(3.7 / 1 / 1.2, \mathrm{~mol} / \mathrm{mol} / \mathrm{mol})$ and that of cellulose is $0.06 \mathrm{~mol} \mathrm{dl}^{-1}$, when dissolved at the concentration of $10 \mathrm{~g} \mathrm{dl}^{-1}$. Therefore, $x$ in eq 11 is in reality at most $0.06 \mathrm{~mol} \mathrm{dl}^{-1}$, although eq 11 is derived by assuming an equimolar reaction between chloral and cellulose. Thus, the equation $(a-x)>0.9 \times 10^{-3}$ always holds, suggesting a preference for the hemiacetal reaction. Comparison of the so-called time conversion curves for the two reactions mentioned above also supports the conclusions obtained here. The experimental results in the NMR study agree well with the above discussion. It should be noted however that when all cellulose molecules in the system are converted into cellulose chlorate the remaining chloral is decomposed into $\mathrm{HCl}$ and dichloroketene. 


\section{Separation of Cellulose Chlorate}

NMR analysis proved that cellulose molecule dissolves and exists in the form of cellulose trichlorate in the D-C-P system. An attempt was made to isolate cellulose chlorate from the solution. A film was prepared by the procedure described in the experimental section. In Figure 11, the IR spectra of the film are shown. The cast film shows an absorption band characteristics of the chlorate residue at $840 \mathrm{~cm}^{-1}$ and a band, characteristics of DMF, remained on the film at $1660 \mathrm{~cm}^{-1}$. In the $840 \mathrm{~cm}^{-1}$ band is included the chloral hydrate residue produced by the reaction between unreacted chloral and water during the casting process. This film was found to dissolve easily in DMF alone. In the case of the film washed with carbon tetrachloride, the $1660 \mathrm{~cm}^{-1}$ band disappeared and the 840 $\mathrm{cm}^{-1}$ band also considerably weakened in intensity, indicating that the remaining DMF and chloral were washed out. The film swelled only in DMF and was not completely dissolved. The chlorine content of the carbon tetrachloride-treated film was found to be $30.6 \mathrm{wt} \%$, which is nearly equal to the theoretical value of $38.2 \mathrm{wt} \%$ for the cellulose monochlorate. The chlorine content of the watertreated film, whose characteristic IR band at 840 $\mathrm{cm}^{-1}$ completely disappeared, was found to be less than $0.1 \mathrm{wt} \%$, indicating a complete regeneration to cellulose, as a result of the hydrolysis of the chlorate residue by water. Thus, cellulose trichlorate could not be isolated from the system under the experimental conditions employed here. It should be noted here that the D-C-P solution of cellulose ex-

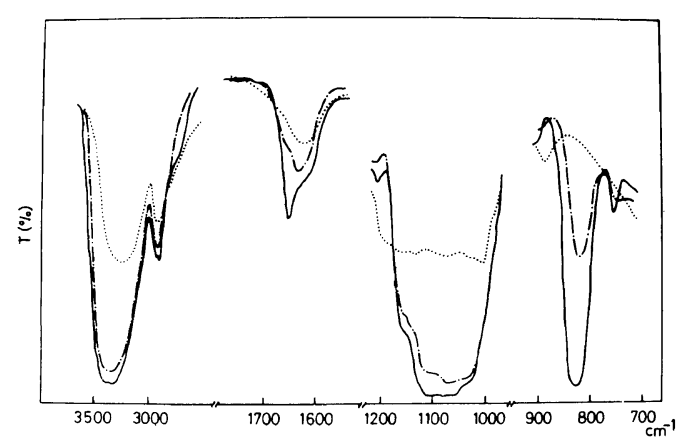

Figure 11. IR spectra for cellulose derivatives recovered from D-C-P system: full line, cast film; broken line, carbon tetrachloride-treated film; dotted line, watertreated film. hibited a $\mathrm{pH}$ value less than 3 when an extremely small amount of water was added to the solution. This acidic nature of the D-C-P system is a direct reflection of the possibility of an $\mathrm{HCl}$ elimination reaction when chloral exists in large excess in the $\mathrm{D}_{-}$ C-P system. The acid existance in the system may facilitate the hydrolysis of the chlorate residue with absorbed water during the recovery process. In fact, as described before, the water-treatment of cellulose monochlorate results in the complete hydrolysis to cellulose. From the IR spectra in Figure 11, it can further be confirmed that the hemiacetal reaction is superior to the dichloroacetylation of cellulose, since the recovered film never shows the carbonyl absorption band.

In Figure 12, the X-ray diffraction pattern of the water-recovered cellulose is shown together with those of natural cellulose and the regenerated cellulose from viscose. A comparison of these patterns reveals that the water-recovered cellulose from D-C-P system is cellulose II.

\section{Dissolving Mechanism of Cellulose in D-C-P System}

The dissolving mechanism of cellulose in the $\mathrm{D}$ C-P system may be summarized as follows.

At first, DMF may weaken the hydrogen bonds existing in cellulose molecules, which are attacked by a complex formed by chloral and pyridine. The carbonyl anion, which is highly anionized by the coordination of pyridine to chloral, may cause a hydrogen-abstraction reaction with $\mathrm{OH}$ groups of cellulose molecules. This reaction may also be accelerated by the pyridinium cation, a part of the complex, which can coordinate with the oxygen atoms of the $\mathrm{OH}$ bond of cellulose. Finally, cellulose reacts with chloral and dissolves in the form of cellulose trichlorate in the solution through a hemiacetal reaction. Since the $\mathrm{HCl}$ elimination reaction (or dichloroketene formation) from chloral molecule is much slower than the hemiacetal reaction, dichloroacetylation of cellulose does not occur in the D-C-P system. However, a portion of the unreacted chloral remaining in the system can be converted into $\mathrm{HCl}$ and dichloroketene. The existence of this acid in the system may influence the hydrolysis of the chlorate residue which reacted with the cellulose molecule during the cellulose recovery process in the system. $\mathrm{HCl}$ may catalyze the hydrolysis of cellulose chlorate to cellulose when the $\mathrm{D}-\mathrm{C}-\mathrm{P}$ solution of cellulose is treated with water. In 


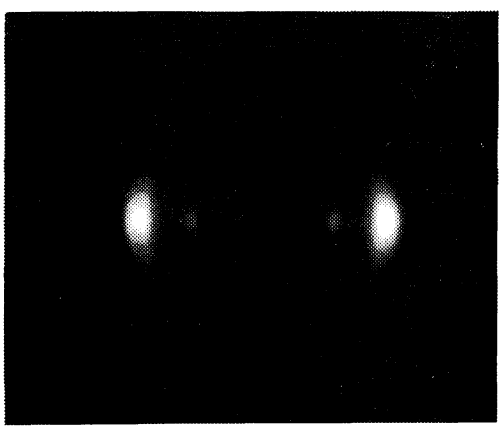

(a)

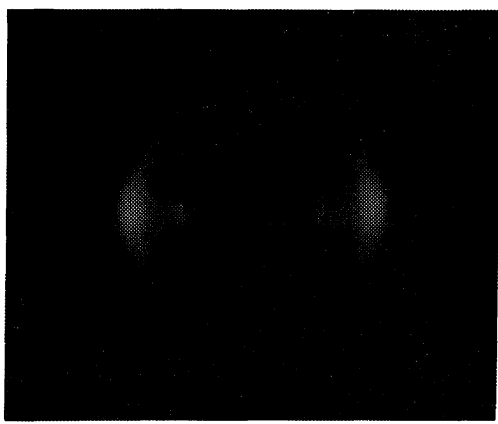

(c)

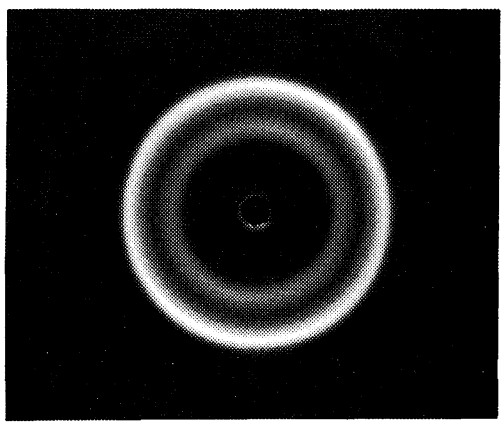

(b)

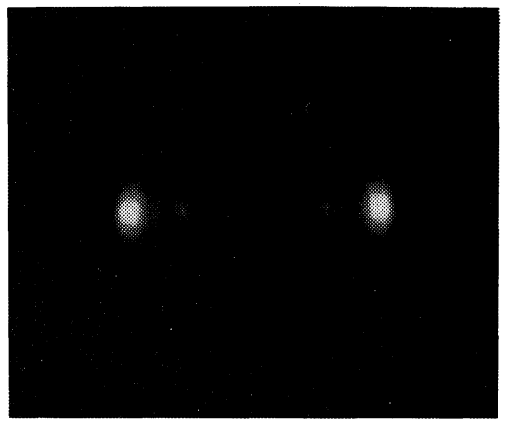

(d)

Figure 12. X-ray diffraction patterns of regenerated cellulose from D-C-P system by water (a), natural cellulose (b), regenerated cellulose from viscose solution (viscose rayon) (c), and regenerated cellulose from cupurammonium solution (d).

spite of the acidic nature of the D-C-P system, the cellulose in the system was found viscometrically not to be degraded by comparing the original cellulose $\left(M_{w}=17.1 \times 10^{4}\right)$ and it's regenerated cellulose $\left(M_{w}=17.7 \times 10^{4}\right)$ in the system by water.

The strong interaction between DMF and cellulose chlorate, detected by a significant shift in it's $\mathrm{OH}$ peak position in NMR spectra, is attributable to the excellent stability of the cellulose solution and also give rise to the strong inhibitory action against any pendant polymerization of chloral onto the cellulose molecules.

\section{REFERENCES}

1. See for example, K. Kamide, Preprint, 27th Summer Seminar, The Society of Polymer Science, Japan, Naeba, Niigata, 1979, p 89.

2. K. H. Meyer, Monatsh. Chem., 81, 151 (1950).

3. T. Nakao, Sen-i to Kogyo, 4, 128 (1971).
4. L. P. Clermont and N. Mannry, J. Appl. Polym. Sci., 18, 2773 (1974).

5. T. Ishii, A. Ishizu, and J. Nakano, Carbohydr. Res., 44, 185 (1977).

6. W. Brown and R. Wikstrom, Eur. Polym. J., 1, 1 (1964).

7. D. C. White, Microkim. Acta, 3, 449 (1967).

8. Bengt G. Ronby, Trans. Faraday Soc., 47, 158 (1951).

9. H. Dolmetsch, Kolloid Z., 106, 174 (1944).

10. K. Kamide, K. Okajima, and T. Matsui, unpublished result.

11. A. Novak and E. Whalley, Trans. Faraday Soc., 55, 1490 (1959).

12. Sadtler Research Laboratory, NMR 6245M (1969).

13. J. Michell, Carbohydr. Res., 12, 453 (1970).

14. See for example, T. Kagiya, Bull. Chem. Soc. Jpn., 41, 767 (1968).

15. N. A. Range, Ed., "Handbook of Chemistry," 10th ed, MacGraw-Hill, New York, N.Y., 1955.

16. See for example, S. Yamazaki and T. Nakao, Polymer Prepr., Am. Chem. Soc., Div. Polym. Chem., 1149 (1972). 